\title{
Global and gene-specific DNA methylation effects of different asbestos fibres on human bronchial epithelial cells
}

\author{
Deniz Öner ${ }^{\mathrm{a}, 1}$, Manosij Ghosh ${ }^{\mathrm{a}, 1}$, Matthieu Moisse ${ }^{\mathrm{b}, \mathrm{c}}$, Radu Corneliu Duca ${ }^{\mathrm{d}}$, Robin Coorens ${ }^{\mathrm{a}}$, \\ Jeroen A.J. Vanoirbeek ${ }^{\mathrm{a}, \mathrm{d}}$, Diether Lambrechts ${ }^{\mathrm{b}, \mathrm{c}}$, Lode Godderis, ${ }^{\mathrm{d}, \mathrm{e}}$, Peter H.M. Hoet ${ }^{\mathrm{a}, *}$ \\ ${ }^{a}$ KU Leuven, Department of Public Health and Primary Care, Unit of Environment and Health, Laboratory of Toxicology, 3000 Leuven, Belgium \\ ${ }^{\mathrm{b}} \mathrm{KU}$ Leuven, Department of Human Genetics, Laboratory for Translational Genetics, Leuven, Belgium \\ c VIB, VIB Center for Cancer Biology, Laboratory for Translational Genetics, Leuven, Belgium \\ ${ }^{\mathrm{d}}$ KU Leuven, Department of Public Health and Primary Care, Unit of Environment and Health, Laboratory for Occupational and Environmental Hygiene, 3000 Leuven, \\ Belgium \\ Idewe, External Service for Prevention and Protection at Work, B-3001 Leuven, Belgium
}

\section{A R T I C L E I N F O}

Handling editor: Yong Guan Zhu

\begin{abstract}
A B S T R A C T
Inhalation exposure to asbestos is associated with lung and pleural diseases in humans and remains a major public health issue worldwide.

Human bronchial epithelial cells (16HBE) were exposed to UICC amosite, crocidolite and chrysotile. Cytotoxicity, genotoxicity, global DNA methylation on cytosine residues (using LC-MS/MS) were investigated at different doses $(2.5-100 \mu \mathrm{g} / \mathrm{ml})$. Gene-specific DNA methylation alterations at the whole genome were investigated using a microarray that interrogates $>450$ thousand CpG sites. Subsequently, gene functional analyses (KEGG pathway, Gene Ontology and functional classification) were performed on genes with differentially methylated gene promoters.

At non-cytotoxic doses, global DNA methylation was altered after $24 \mathrm{~h}$ exposure to amosite and crocidolite $(>2.5 \mu \mathrm{g} / \mathrm{ml}$ ). Exposure to amosite and crocidolite (amphibole type asbestos) induced both hypomethylation and hypermethylation at single $\mathrm{CpG}$ site and gene promoter levels whereas exposure to chrysotile (serpentine type asbestos) induced hypomethylation at the gene promoter level.

Gene functional classification analyses revealed that all types of asbestos fibres induce alterations on GOclusters i.e. on regulation of Rho-protein signal transduction, nucleus, (e.g. homeobox genes), ATP-binding function and extracellular region (e.g. WNT-group of genes). These differentially methylated genes might contribute to asbestos-related diseases in bronchial cells.
\end{abstract}

\section{Introduction}

During the 20th century three types of asbestos were extensively used. These types of asbestos are amosite, known as brown asbestos; crocidolite, known as blue asbestos and chrysotile, amounted to around $90 \%$ of the overall asbestos usage worldwide (Raffn et al., 1989), known as white asbestos. Chrysotile is in the group of serpentine asbestos and is shaped in curly fibres. The fibres have a central hole, can breakdown easily in acidic environments (e.g. lysosomes) and clears out relatively easily from the lungs over the years after inhalation (Bernstein et al., 2013). Amosite and crocidolite are in the group of amphibole asbestos and are shaped as straight fibres and do not easily breakdown into shorter fragments. The clearance of amosite and crocidolite from the lungs is much slower compared to chrysotile (Bernstein et al., 2013). For instance, the estimated half-life of amosite and crocidolite can be in the order of decades whereas the estimated half-life of chrysotile can be in the order of months (Churg, 1994; Mossman and Churg, 1998). All three types of asbestos fibres are classified as class-I carcinogen by the International Agency for Cancer Research (IARC) (IARC Monographs, 2012). Although asbestos usage has now been banned in many developed countries, the incidence of lung mesothelioma is still increasing due to the long latency period (e.g. over 30-40 years) (Robinson, 2012; Tomasson et al., 2016).

Notwithstanding large efforts and detailed description of several toxicity-related mechanisms, there is a lack of established 'molecular markers' which may detect asbestos-induced disease initiation or

\footnotetext{
* Corresponding author.

E-mail address: Peter.hoet@kuleuven.be (P.H.M. Hoet).

${ }^{1}$ First two authors have equal contribution.
} 
progression. This is mainly because malignant mesothelioma shows irregular chromosomal abnormalities and include lack of specific DNA mutations or driver oncogenes (Humans, 2012; Krismann et al., 2002; Sugarbaker et al., 2008). Since the first step of carcinogenesis include genetic and epigenetic abnormalities (Schmutte and Fishel, 1999), studies focused on investigation of epigenetic profiles between mesothelioma and lung cancer tissues, in aim to identify prognostic and diagnostic signatures (Mossman, 2017a). These investigations show that epigenetic profiles distinguish mesothelioma from normal pleura when 803 cancer associated gene promoters were studied (Brock C. Christensen et al., 2009). Another study examined 6157 CpG islands and indicated hypermethylation of KAZALD1, MAPK13 and TMEM30b genes (Goto et al., 2009). In addition, hypermethylation of cell cycle control pathways genes including APC, CCND2, CDKN2A, CDKN2B, HPPBP1 and RASSF1 were noted to be hypermethylated in mesothelioma samples (Christensen et al., 2008). Loss of methylation of MSLN gene has been shown in tumour tissues (Nelson et al., 2011). Finally, hypermethylation of ESR1, SLC6A20 and SYK genes were noted in mesothelioma tissues (Tsou et al., 2007). Nevertheless, these studies were performed on clinical samples, and a lack of detailed in vitro analysis on the global and gene-specific DNA methylation alterations after exposure to different types of asbestos.

Epigenetic alterations on certain genes and gene groups might trigger cellular malignancies after environmental or occupational asbestos exposure. Epigenetics, by definition, is the study of heritable modifications on DNA, which alter gene expression without any modification of the DNA sequence. One of the most known and studied epigenetic mechanisms is the DNA methylation on cytosine residues followed by guanidine, i.e. CpG sites. Aberrant alterations on the DNA methylation are an important parameter of the onset of diseases including cancer (Baylin, 2005; Kulis and Esteller, 2010). Generally, DNA hypermethylation on the enhancer or transcription start sites inhibits the binding of transcription factors and subsequent initiation of transcription whereas DNA hypomethylation might activate the gene transcription by allowing binding of the transcription factors. In addition, global DNA hypomethylation might trigger incorrect segregation of the chromatids during cell divisions, inducing aberrant micronuclei formation. Alterations at gene-specific methylation and global methylation levels, therefore, affect cellular fate (e.g. alterations in apoptosis, cellular differentiation, migration) and increase susceptibility to the disease formation (Baccarelli and Bollati, 2009).

In this study, the main aim is to identify DNA methylation alterations on gene promoter regions of specific genes and gene groups after different types of asbestos exposure in order to investigate mechanisms of asbestos-related carcinogenesis. To do so, we investigated cytotoxicity, genotoxicity, global and gene-specific methylation alterations after exposure to amosite and crocidolite (amphiboles), and chrysotile (serpentine) in bronchial epithelial cells (16HBE), using liquid chromatography mass spectrometry (LC-MS/MS) and a genome-wide microarray, Illumina $450 \mathrm{~K}$.

\section{Materials and methods}

\subsection{Asbestos fibres}

The asbestos samples were obtained from The Union for International Cancer Control (UICC) standard reference asbestos fibres. Amosite South African, Crocidolite South African and Chrysotile "A" Rhodesian. Measurement of dry asbestos fibres were performed in IDEWE (External Service for Prevention and Protection at Work), under safety cabinets. All the laboratory experiments were performed under the HEPA-filter laminar flow with safety clothing and contaminated materials are discarded considerably as required by Belgian law.

Prior to the experiment, the stock of asbestos $(1 \mathrm{mg})$ was dispersed in distilled water (Versylene, Fresenius, France) containing $2 \%$ of fetal bovine serum (FBS) (Merelbeke, Belgium) and sonicated in a bath sonication (1510, Branson) for $10 \mathrm{~min}$. The working concentrations were diluted $(1: 10)$ from the intermediate concentrations in order to obtain the same serum levels in each suspension.

\subsection{Cell cultures and treatments}

16HBE14o- (16HBE), human bronchial epithelial cells were used for the asbestos exposure studies. The cells were kindly provided by Dr. Gruenert (University of California, San Francisco, USA). The cell culture medium contained Dulbecco's modified eagle medium DMEM/F12 medium supplemented with $5 \%$ of FBS and $\% 1$ of penicillin/streptomycin $(10,000 \mathrm{U} / \mathrm{ml})$, L-glutamine $(200 \mathrm{mM})$, fungizone $(250 \mu \mathrm{g} / \mathrm{ml})$, each. The cells were kept in an incubator at $37^{\circ} \mathrm{C}$, in a $100 \%$ humidified atmosphere containing $5 \% \mathrm{CO}_{2}$. When the cells reached confluency, $2.5 \times 10^{5}$ cells were split to a new T25 flask. The cells were harvested for epigenetic analyses when passage number 4 was reached. Before the each experiment, $80 \%$ of the confluence of the cells was aimed to be reached before asbestos exposure. The supplies for cell culturing were purchased from Invitrogen (Merelbeke, Belgium).

\subsection{Cytotoxicity}

The cell viabilities were analysed by a standard protocol of water soluble tetrazolium salts-1 (WST-1) assay. The 16HBE cells were treated with chrysotile, amosite and crocidolite fibres for $24 \mathrm{~h}$. The assay was performed in three independent experiments including three biological replicates.

\subsection{Comet assay}

An alkaline comet assay was performed to assess DNA damage using Trevigen CometAssay Kit (Gentaur, Kampenhout, Belgium), according to the manufacturer's protocol. Cells were analysed using a fluorescence microscope. In total, 50 cells from 2 replicates of each exposure were measured for the DNA damage by means of the \% DNA Tail metric using the CaspLab program (casplab 1.2.3b2). $\mathrm{H}_{2} \mathrm{O}_{2}$ was used as a positive control and resulted in an increased number of hedgehogs.

\subsection{DNA extraction}

The cells were exposed with amosite, crocidolite and chrysotile (concentrations range: $2.5,5,25$ and $100 \mu \mathrm{g} / \mathrm{ml}$ ) for $24 \mathrm{~h}$. In both experiments, untreated and vehicle-treated cells were used as a negative control and Decitabine- (Sigma Aldrich, Brussels, Belgium, DNA hypomethylating agent) treated wells were used as a positive control. Six replicates were performed. The cells were proceeded with DNA extraction performed using the Qiagen DNA/RNA extraction mini kit (QIAGEN, Antwerp, Belgium).

\subsection{Global DNA methylation alterations}

Global DNA methylation on total cytosine residues was quantified using LC-MS/MS, as described previously by Godderis et al. (Godderis et al., 2015). The absolute concentration of DNA 5-methylcytosine (5$\mathrm{mC}$ ) levels were calculated according to a calibration curve with known concentrations.

\subsection{Gene-specific alterations}

The selection of the dose for gene-specific alterations analysis was based on our analysis in which a marginal increase in global methylation was detected on the concentrations higher than $2.5 \mu \mathrm{g} / \mathrm{ml}$ and literature in which a marginal increase in genotoxicity and gene expression alterations were noted after same dose of asbestos exposure, in vitro (Asakura et al., 2010; Dopp et al., 2005; Kodama et al., 1993; Srivastava et al., 2010). 
(\%) DNA 5mdc level

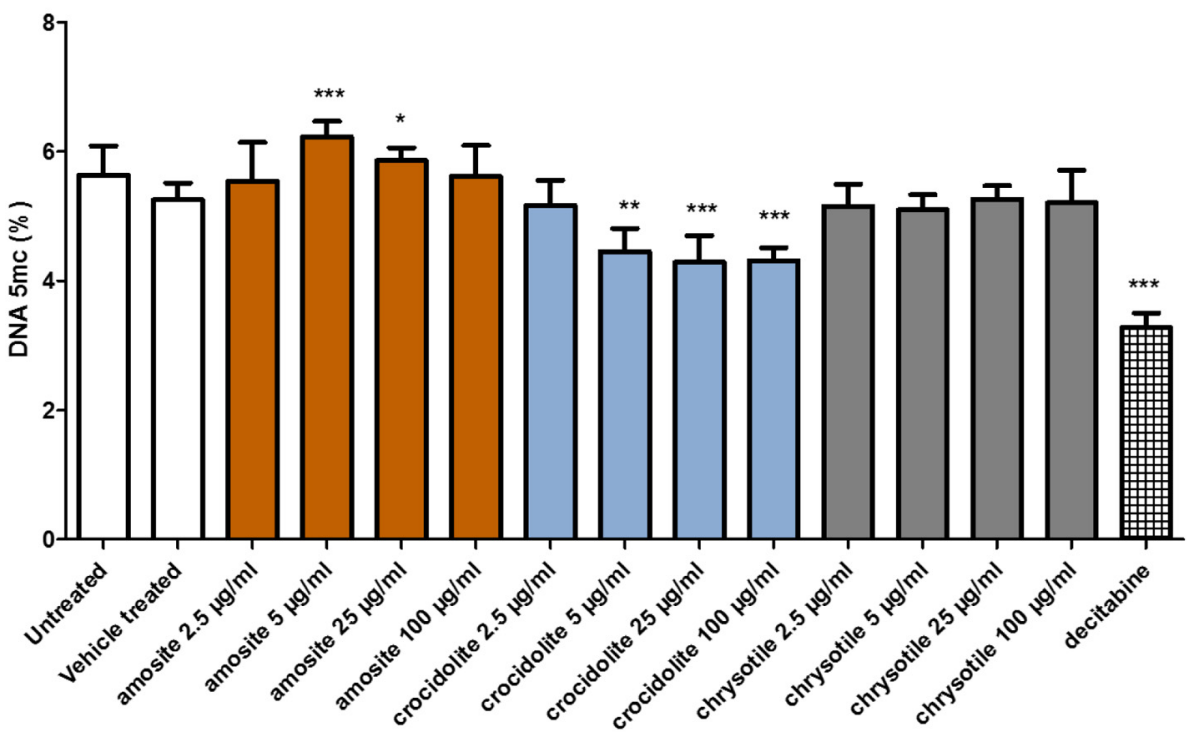

Fig. 1. Global cytosine DNA methylation alterations induced by asbestos fibres. The percentage of (\%) 5$\mathrm{mC}$ is shown on the $\mathrm{y}$-axis. The asbestos exposure type and the concentrations were demonstrated on the x-axis. The global DNA methylation levels after amosite exposure are shown in brown-orange bars, after crocidolite exposure are shown in blue bars and after chrysotile exposure are shown in gray bars. The significant DNA methylation alterations is depicted as * $(\mathrm{p}<0.05), \quad * * \quad(\mathrm{p}<0.01)$, and $* * *$ $(\mathrm{p}<0.001)$. The statistical analysis was conducted using a one-way ANOVA with Dunnett's multiple comparison against values from vehicle-treated cells. $(\mathrm{N}=6)$. (For interpretation of the references to colour in this figure legend, the reader is referred to the web version of this article.)
After the DNA extraction, bisulfite conversion was performed in order to convert non-methylated cytosine into uracil in the genomic DNA using the EZ DNA mini kit (Zymo Research, Orange, CA) according to the manufacturer protocol. Genome-wide DNA methylation profiles were assessed by using Infinium HumanMethylation450 BeadChip Array which assesses $>450,000$ individual CpG sites. The amosite-, crocidolite- and chrysotile-exposed cells were compared with the untreated (-control) and vehicle cells. Decitabine-exposed cells were clustered by differential methylation and excluded from the analysis.

\subsection{Bioinformatics}

Data pre-processing was performed by using the Bioconductor Rpackages (R Core Team, 2017). The initial quality check was performed with the 'minfi' package and type I and II probe normalizations were performed with the 'SWAN' method (Aryee et al., 2014; Maksimovic et al., 2012). The density plots and the multidimensional scaling (MDS) plots of the data analysis, after SWAN normalization, is provided in Supplementary (S.) Figs. 1 and 2, respectively. These analyses indicate high quality and accuracy between the samples. For data annotation and further filtering, the 'IMA' package was used (Wang et al., 2012).

For each differentially methylated CpG site, the 'limma' package was used employing a linear modelling approach and batch effect was corrected by Bayes statistics (Smyth, 2005; Wang et al., 2012). Individual CpG sites were annotated to the genes based on illumina annotation database.

Gene promoter regions were defined as the mean level of all CpG sites defined by the Ensemble gene annotation version 75 .

Methylation levels values, i.e. $M$ values, were used over $\beta$ values since it is preferred for the small sample sizes $(<10)$ (Zhuang et al., 2012). The following equation was used:

$M=\log _{2} \frac{\beta}{1-\beta}$

Individual $p$ values were FDR (False Discovery Rate) corrected and defined as $q$ values (Benjamini and Hochberg, 1995).

\subsection{Microarray analysis}

The samples were stratified according to the type of exposure: amosite, crocidolite, chrysotile, vehicle and untreated (-control).

Clustering, using a heatmap, was generated using the 'RPMM' package using top 500 differentially methylated genes by their gene promoters. Chromosome-wide Manhattan plots were generated using the 'qqman' package (Turner, 2014).

Three different types of gene set analyses were performed using the DAVID web-tool (Ashburner et al., 2000; Huang et al., 2009). First, the subset of differentially methylated genes $(q$ value $<0.05)$ were investigated for their gene function according to the GO consortium (The Gene Ontology Consortium 2000, http://geneontology.org/) (Ashburner et al., 2000; Consortium, 2015). Second, the genes were investigated for their involvement in cell pathways using the Kyoto Encyclopedia of Genes and Genomes (KEGG) database (http://www. genome.jp/kegg/) (Ogata et al., 1999). As a background, the DAVIDsupported 'Homo sapiens' gene set was used. The gene set enrichment analysis was implemented to find out those differentially methylated genes that showed significance on the GOs or the KEGG pathways compared to an analysis of randomized genes. Third, functional gene clustering analyses were performed in order to classify the gene functional groups in a ranked manner using fuzzy heuristic partitioning (through medium or high stringency).

\subsection{RT-PCR assay}

Investigation of gene expression of selected genes was performed using reverse transcription-polymerase chain reaction (RT-PCR) assay in an independent experiment. The genes were selected based on our microarray data analysis and literature research. The genes selected were representative of Ras oncogene subfamily (MRAS); PI3K group (PIK3R5); WNT gene family (WNT7A), transcription factors (TCF7) and Homeobox group (HOXB3), which were found to differentially methylated from our experiments. Different asbestos fibres were exposed on $16 \mathrm{HBE}$ cells $(2.5 \mu \mathrm{g} / \mathrm{ml})$ in six-well plates in four independent replicates $(N=4)$. RNA is extracted immediately using AllPrep DNA/RNA mini kit (Qiagen, Belgium). Thermo Scientific 2000c Nanodrop was used to check the quality and the quantity of the RNA. Complementary DNA (cDNA) conversion was performed using SuperScript III First strand kit (Invitrogen, Belgium) according to the protocol of the kit. The genes were amplified with Platinum ${ }^{\circledast}$ SYBR $^{\circledast}$ Green qPCR SuperMix-UDG (Invitrogen, Belgium) and Westburg Eco 48 wells. As a housekeeping gene, GAPDH gene was used. $2^{-\Delta \Delta \mathrm{Ct}}$ values were calculated to show the fold change relative to the vehicle controls.

Primers for the gene amplification were designed in bioinformatics tool, primer bank (https://pga.mgh.harvard.edu/primerbank/index. 
a)

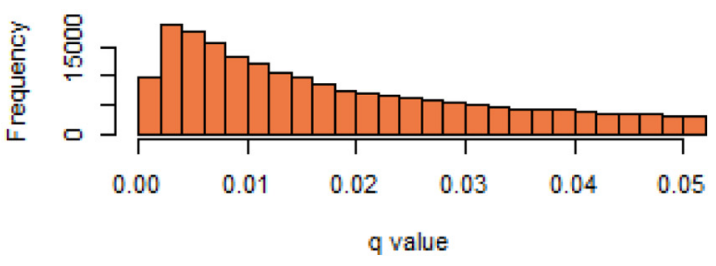

c)

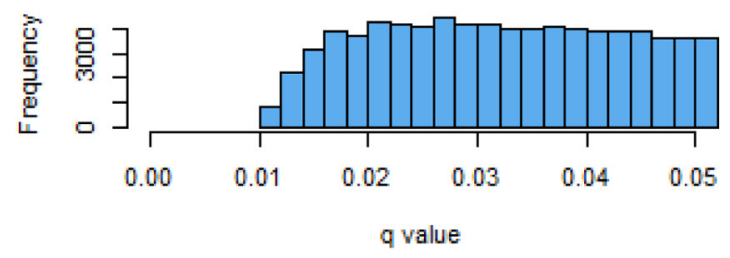

e)

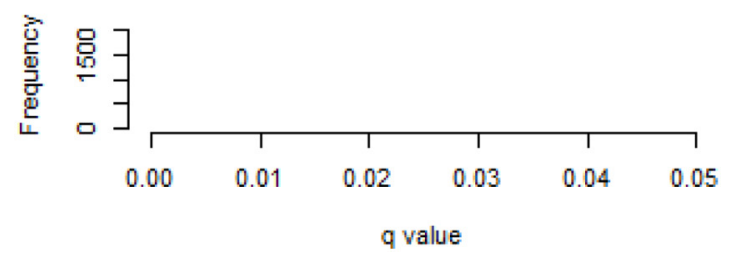

b)

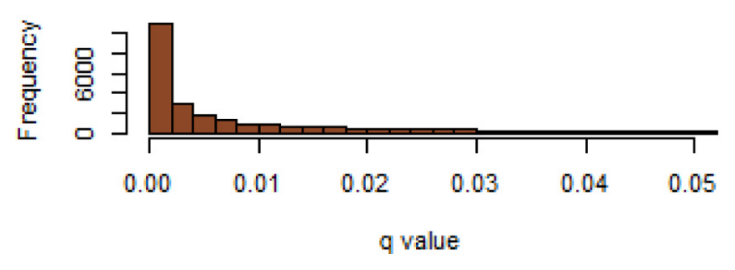

d)

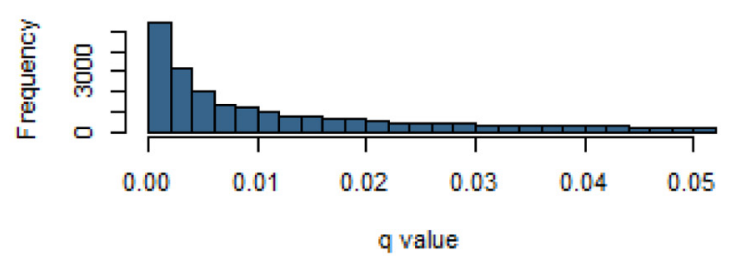

f)

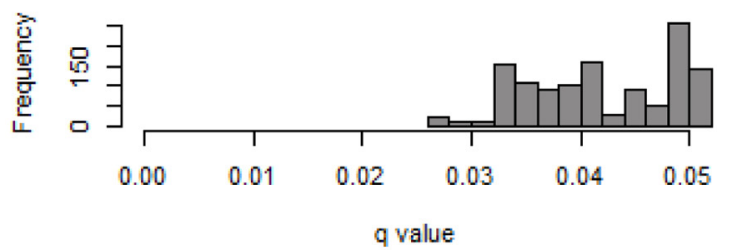

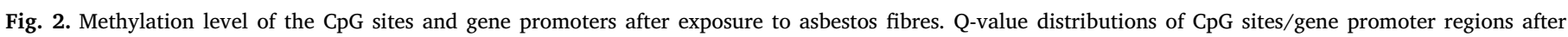

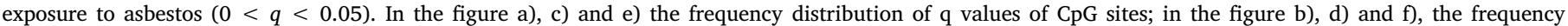

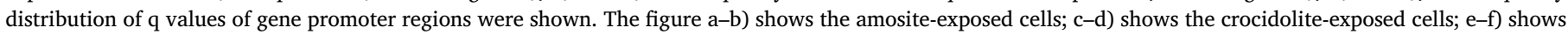
the chrysotile-exposed cells.

Table 1

Primer sequences of the selected genes for RT-PCR.

\begin{tabular}{ll}
\hline Primer name & Primer sequence \\
\hline MRAS forward & ACAAGGTCGATTTGATGCACT \\
MRAS reverse & GCACTGGTTTCTATGTACGGAAT \\
PIK3R5 forward & CTTCCACGCTACGTGTTGTG \\
PIK3R5 reverse & TGAAGTTTGAAGAACCGTGTGAG \\
WNT7A forward & CTGTGGCTGCGACAAAGAGAA \\
WNT7A reverse & GCCGTGGCACTTACATTCC \\
TCF7 forward & TTGATGCTAGGTTCTGGTGTACC \\
TCF7 reverse & CCTTGGACTCTGCTTGTGTC \\
HOXB3 forward & AACGCCTTACACTCCATGACC \\
HOXB3 reverse & GACGTGCGGCTCATACTCG \\
GAPDH forward & TGGTATCGTGGAAGGACTCA \\
GAPDH reverse & CCAGTAGAGGCAGGGATGAT \\
\hline
\end{tabular}

html) and NCBI primer designing tool (https://www.ncbi.nlm.nih.gov/ tools/primer-blast/) (Spandidos et al., 2008, 2010; Wang and Seed, 2003; Ye et al., 2012). The primers are listed in Table 1.

\subsection{Statistics}

The statistical analyses to assess the cytotoxicity and genotoxicity of the asbestos were performed by a one way ANOVA with Dunnett's multiple comparison using GraphPad Prism version 5.03 for windows (GraphPad Software, La Jolla California USA, www.graphpad.com). Unpaired two-tailed $t$-test (95\% confidence interval) was used for RTPCR assay (GraphPad Prism 5.03). The statistical analysis of the epigenomic data was performed with above-mentioned (materials and methods, bioinformatics section) methods using R/Bioconductor.

\section{Results}

\subsection{Cytotoxicity and DNA damage}

Depicted in supplementary (S.) Fig. 3, asbestos fibres induced slight but dose-dependent decrease in cell viability after exposure to all types of asbestos. Significant cytotoxicity was noted for $200 \mu \mathrm{g} / \mathrm{ml}$ of crocidolite and chrysotile asbestos exposure (cf. S. Fig. 3-b and "S. Fig. 3-c).

The DNA damage was assessed by alkaline comet assay, which detects DNA strand breaks, using four different non-cytotoxic concentrations: $2.5,25$ and $100 \mu \mathrm{g} / \mathrm{ml}$. A significant dose-dependent DNA damage was noted for all asbestos types, see S. Fig. 4. Chrysotile-exposed cells increased the DNA damage in vast amounts in comparison to amosite- and crocidolite-exposed cells.

\subsection{Global DNA methylation alterations}

Depicted in Fig. 1, exposure to amosite and crocidolite resulted in global hypermethylation and hypomethylation, respectively, above the concentration of $2.5 \mu \mathrm{g} / \mathrm{ml}$. On the other hand, exposure to chrysotile did not affect the global DNA methylation levels at the tested concentrations.

\subsection{Gene-specific DNA methylation alterations}

In Fig. 2-a, 2-c and 2-e, the frequency distributions of $q$ values of CpG sites for each type of asbestos exposure (amosite, crocidolite and chrysotile, respectively) are depicted. Since regional methylation levels around the gene promoter can alter gene expression, gene promoter methylation levels were also measured. In Fig. 2-b, 2-d and 2-f, the 


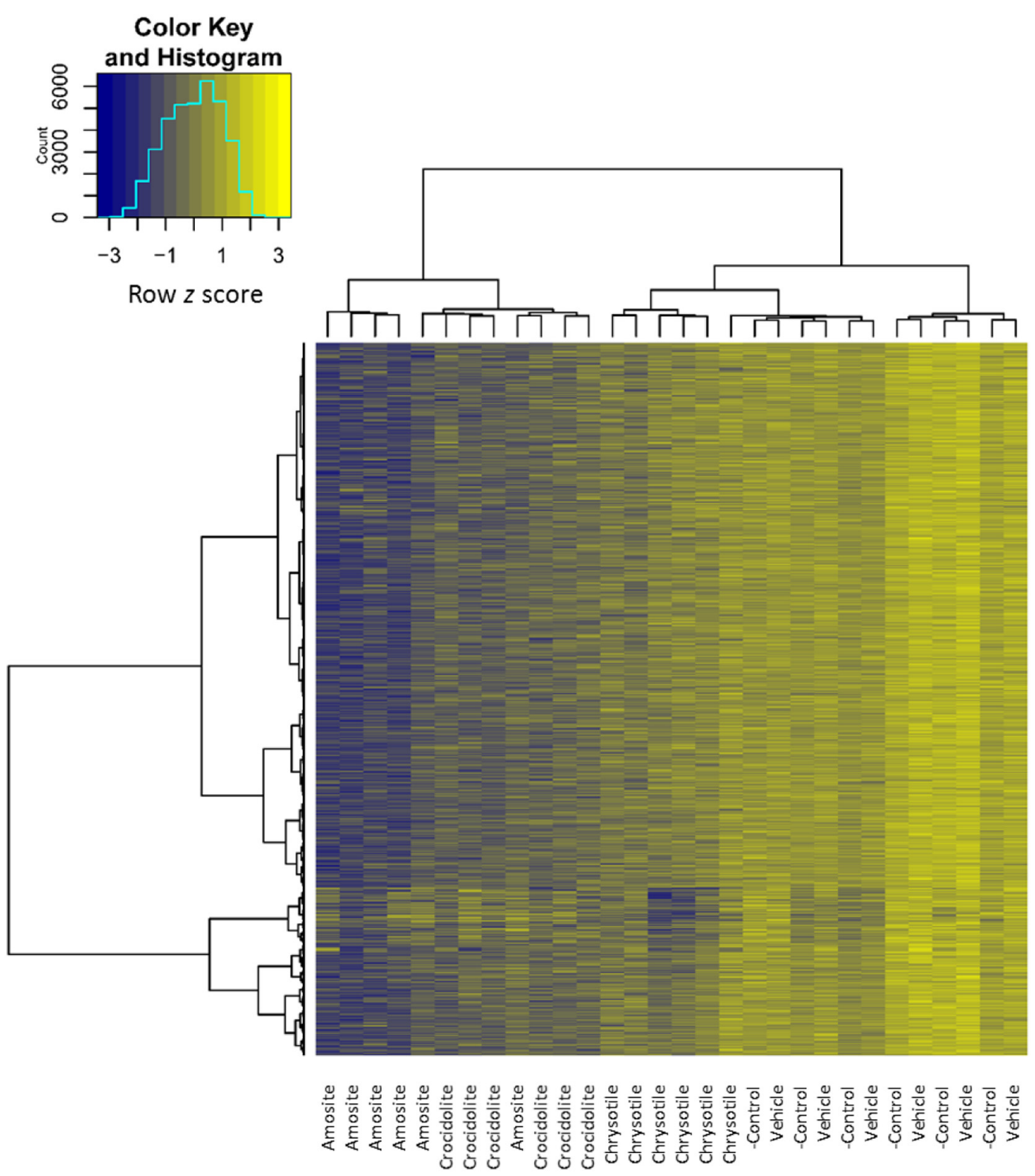

Fig. 3. Hierarchical clustering of gene-specific DNA methylation states of asbestos-exposed cells. The clustering and the DNA methylation states were analysed using a heatmap. The colour key histogram shows the DNA methylation levels. A blue colour indicates hypomethylation and a yellow colour indicates hypermethylation based on the $\mathrm{z}$ score. The dendrograms at the top of the heatmap show the clustering of the samples. The dendogram at the left side shows the differential clustering of asbestos-exposed cells. (For interpretation of the references to colour in this figure legend, the reader is referred to the web version of this article.)

frequency distributions of $q$ values of gene promoter regions for each type of asbestos exposure (amosite, crocidolite and chrysotile, respectively) are depicted. As seen from the figures, exposure to amosite and crocidolite induced increased differential methylation both at gene promoters and at the single CpG sites, whereas exposure to chrysotile resulted in increased differential methylation only at the gene promoters regions.

\subsection{Hierarchical clustering of the gene-specific DNA methylation states}

In Fig. 3, a heatmap and the corresponding hierarchical clustering analysis using top differentially methylated gene promoters after amosite-, crocidolite- and chrysotile-exposed cells are depicted. Differential clustering of asbestos-exposed cells was observed. Two main branches were seen. First branch includes the group of amosite- and crocidolite-exposed cells. Within this group amosite exposed cells formed another sub-group by decreased methylation. The second branch contains the group of chrysotile-exposed cells and the controls. Within this group, chrysotile-exposed cells formed a distinct sub-group by decreased methylation levels. This analysis reveals that all asbestos types induced differential methylation (mainly hypomethylation) after exposure to asbestos. In addition, different methylation profiles were noted between two asbestos types [amphibole (amosite and crocidolite) and serpentine (chrysotile)].

\subsection{Differentially methylated gene promoters}

Differentially methylated gene promoters were further investigated since aberrant methylation or demethylation of gene promoters can affect the binding of the transcription factors and alter the subsequent gene expression. For amosite- and crocidolite-exposed cells, the genes with the differential methylation at both $\mathrm{CpG}$ sites and gene promoter regions were subset. Demonstrated in Fig. 4, the exposure to amosite induced differential methylation on 9107 genes, 17 of which were 


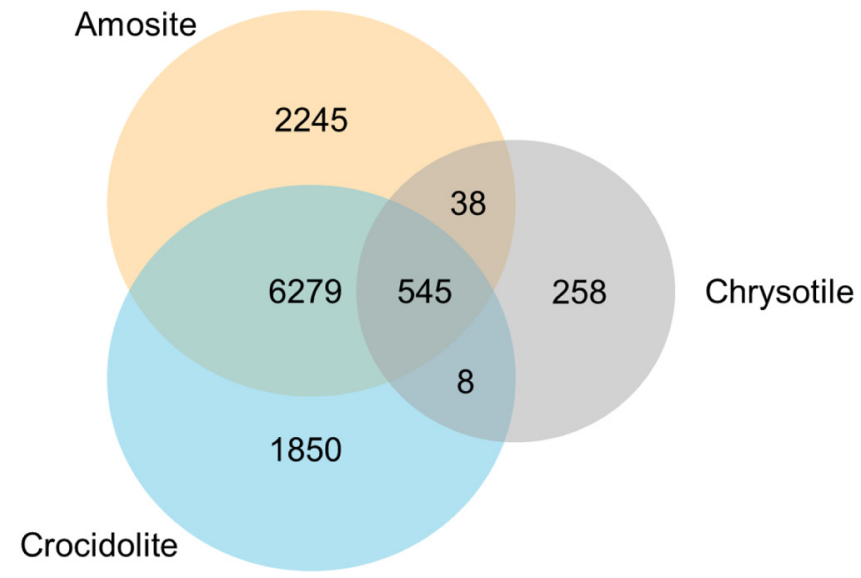

Fig. 4. The Venn diagram represents the number of differentially methylated genes and the overlap between different types of asbestos fibres.

hypermethylated, and the exposure to crocidolite induced alterations on 7576 genes, 4 of which were hypermethylated. The hypermethylated genes were summarized in the supplementary information. 6824 genes were overlapped between amosite- and crocidolite-exposed cells and all were hypomethylated. Exposure to chrysotile induced 849 differentially methylated genes and all were hypomethylated at their gene promoter regions. 545 genes were differentially methylated by all types of asbestos fibre exposure.

The subsequent analysis involves functional gene analysis. The analyses contain three levels: 1) using differentially methylated genes induced by amosite and crocidolite exposure, 2) chrysotile exposure and 3) the overlapped genes for both types of exposures.

\subsection{Functional gene analyses for amosite and crocidolite}

The gene promoters that are differentially methylated after exposure to amosite and crocidolite were processed for functional analysis in order to determine their role in cellular signalling. Demonstrated in S. Tables 1 and 3 (for amosite and crocidolite, respectively), the most enriched GO terms included: 'regulation of transcription from RNA polymerase II promoter and transcription' and 'DNA-templated'. Demonstrated in S. Table 2 and 4 (for amosite and crocidolite, respectively), the most enriched KEGG pathways included: 'pathways in cancer', 'MAPK signalling pathway' and 'oxytocin signalling pathway'.

Because of high similarity (either functional or by gene number) between the two asbestos fibres (amosite and crocidolite and referred as amphiboles) and for simplicity, the shared differentially methylated genes after exposure to both type of asbestos, were re-analysed to determine general conclusion for epigenetic effects. In S. Table 5-a, the gene ontology analysis identified, after exposure to amphibole fibres and ranked by the FDR-corrected $p$ values, the following GO terms: 'positive regulation of transcription from RNA polymerase II promoter', 'negative regulation of transcription from RNA polymerase II promoter', 'transcription from RNA polymerase II promoter', 'chemical synaptic transmission', 'transcription, DNA-templated'. In addition, 'canonical WNT signalling pathway' was also noted. In S. Table5-b, the KEGG pathway analysis identified, after exposure to amphibole fibres and ranked by the FDR-corrected $p$ values, the following cell pathways: 'MAPK signalling pathway', 'Rap1 signalling pathway', 'calcium signalling pathway', 'signalling pathways regulating pluripotency of stem cells', 'pathways in cancer', 'cholinergic synapse', 'oxytocin signalling pathway', 'glutamatergic synapse', 'cAMP signalling pathway', 'neuroactive ligand-receptor interaction', 'cGMP-PKG signalling pathway'. In S. Table 6, the gene cluster analysis is reported. Since the DAVID cluster analysis requires a maximum of 3000 genes for cluster analysis, the cut-off value for detection of significance was set when at $q<0.02$.
Table 2

Gene functional classification using differentially methylated that is altered by all types of asbestos fibres (DAVID, 6.8, 15/06/2017).

\begin{tabular}{lll}
\hline No & Full gene name & Gene symbol \\
\hline \multicolumn{2}{l}{ Gene group 1: Nucleus (enrichment score: 2.17) } & \\
1 & Homeobox D12 & HOXD12 \\
2 & Forkhead box I2 & FOXI2 \\
3 & Homeobox D11 & HOXD11 \\
4 & Nuclear factor I X & NFIX \\
5 & Homeobox C11 & HOXC1 \\
6 & GTF2I repeat domain containing 1 & GTF2IRD1 \\
7 & One cut homeobox 1 & ONECUT1 \\
8 & Ventral anterior homeobox & VAX1 \\
9 & Homeobox B7 & HOXB7 \\
10 & Homeobox B3 & HOXB3 \\
11 & Caudal type homeobox 2 & CDX2 \\
12 & Upstream binding protein 1 (LBP-1a) & UBP1 \\
13 & Heat shock transcription factor 4 & HSF4 \\
14 & BARX homeobox 1 & BARX1 \\
15 & Homeobox A3 & HOXA3 \\
16 & Forkhead box D2 & FOXD2 \\
17 & SATB homeobox 2 & SATB2 \\
18 & LIM homeobox 2 & LHX2 \\
19 & T-box 4 & TBX4 \\
20 & POU class 2 homeobox & POU2F2 \\
21 & T-box, brain 1 & TBR1 \\
22 & T-cell leukemia homeobox 2 & TLX2 \\
& & \\
\hline
\end{tabular}

Gene group 2: Regulation of Rho protein signal transduction (enrichment score: 1.98) like

2

Genc

Gene group 4: Extracellular region (enrichment score: 1.32)

1 Wnt family member 7A

2 Wnt family member 10A WNT10A

3 Wnt family member 5B WNT5B

$4 \quad$ Wnt family member $11 \quad$ WNT11

Gene group 5: Ankyrin repeat domains (enrichment score: 1.25)

$\begin{array}{lll}1 & \text { NFKB inhibitor delta } & \text { NFKBID } \\ 2 & \text { Ankyrin repeat domain 11 } & \text { ANKRD11 } \\ 3 & \text { Ankyrin repeat domain 30A } & \text { ANKRD30A } \\ 4 & \text { Ankyrin repeat domain 52 } & \text { ANKRD52 }\end{array}$

The analysis revealed the following top five clusters: 'DNA binding', e.g. homeobox (HOX) genes, 'transmembrane region', 'calcium-ion binding' or 'cell adhesion', e.g. (proto)cadherins, 'nucleotide exchange factor 
activity', e.g. RhoGEFs, 'transcription regulation', e.g. forkhead boxes.

\subsection{Functional gene analyses for chrysotile}

Using differentially methylated genes after chrysotile exposure, functional gene analyses were performed. Using a gene functional classification tool, seven gene clusters were noted, a cut-off $\geq 1$ (summarized in S. Table 7). Differentially methylated genes were clustered as genes that are related to 'ATP-binding function', 'Regulation of RHOprotein signal transduction', i.e. RHO guanidine nucleotide exchange factors, 'nucleus', i.e. homeobox (HOX) genes 'extracellular region' i.e. wingless/integrated (WNT) group of genes, 'nucleotide binding' i.e. RNA binding motif protein, 'ankyrin repeat domains' i.e. NF-kB inhibitor delta (NF-kBID), 'oxidation-reductation process', i.e. cytochrome P450 family. Looking at individual genes one can say that the alterations on transcription factors, genes on MAPK signalling, cyclic adenosine monophosphate (Camp) and NF- $\mathrm{kB}$ signalling were evident. No functional annotation enrichment was concluded using the GO and the KEGG databases.

\subsection{Functional gene analyses using shared genes}

A gene functional classification analysis was conducted on the genes that are differentially methylated by gene promoters after exposure to all types of asbestos. Since it is known that all types of asbestos are carcinogenic, these sets of shared genes might provide useful information regarding the disease progression.

Functional gene classification analyses were performed using the shared 545 genes (see Fig. 6). As shown in Table 2, five clusters were identified. These sets of clusters include genes that are related to ' $n u$ cleus' i.e. HOX genes, 'regulation of Rho protein signal transduction' i.e Rho guanine nucleotide exchange factors, 'ATP-binding function' i.e. tyrosine kinases and 'extracellular region' i.e. WNT group of genes and 'Ankyrin repeat domains' i.e Ankyrin proteins and NF-kBID.

a) HOXB3

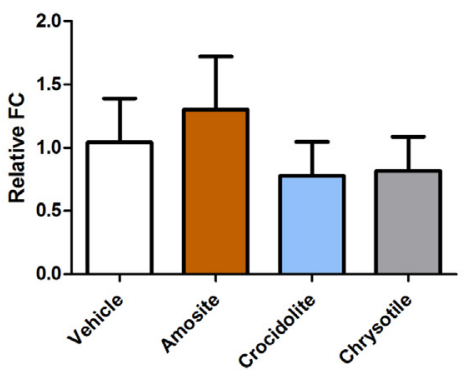

b) TCF7

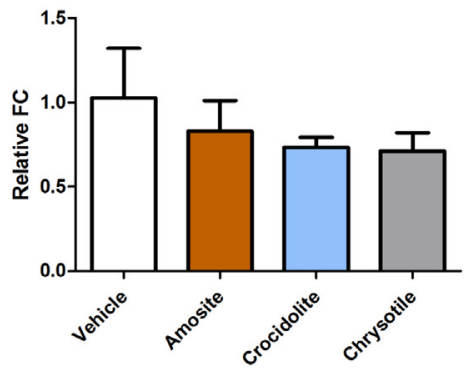

\subsection{Gene expression changes on selected genes}

According to the findings of the whole genome DNA methylation microarray (Illumina450K), the expression of HOXB3, TCF7, WNT7A, MRAS and PIK3R5 genes were investigated using RT-PCR (Fig. 5). Significant downregulation of MRAS gene was noted after exposure to crocidolite $(2.5 \mu \mathrm{g} / \mathrm{ml})$ and non-significant down regulation for chrysotile exposure (Fig. 5). Although substantial down regulation was observed for other genes such as TCF7, HOXB3, PIK3R5, and WNT7A, significance was not reached.

\section{Discussion}

Inhalation of asbestos has been associated with a wide range of pulmonary diseases including malignant mesothelioma and lung carcinomas (Kamp, 2009). Unfortunately, early diagnosis of asbestosmediated lung diseases is limited since asbestos-exposure mediated lung tumors have been found to be characterized by heterogeneous and distinctive mutations, tumour biology and genomic abnormalities (Krismann et al., 2002; Sugarbaker et al., 2008). Therefore, epigenetic approaches have become an alternative to identify early biomarkers of asbestos exposure and disease (Mossman, 2017b). Epigenetic profiles have been shown to appear different between the diseased tissues and non-diseased tissues and might predict the prognosis of the disease, indicating that an investigation of the DNA methylation alterations could be promising to detect asbestos exposure and diseases (Brock C Christensen et al., 2009; Fischer et al., 2006; Goto et al., 2009; Laszlo et al., 2015; Tsou et al., 2005, 2007).

We aimed to study non-cytotoxic doses of asbestos fibres, considering amosite, crocidolite (amphibole types of asbestos) and chrysotile (serpentine type of asbestos), in order to ensure cellular viability while studying the DNA methylation alterations. Our study indicated significant cytotoxicity (by WST-1 assay) at only $200 \mu \mathrm{g} / \mathrm{ml}$ (highest dose) of crocidolite and chrysotile exposure, suggesting that the majority of cells remained alive after $24 \mathrm{~h}$ of exposure to asbestos fibres. Asbestos exposure has been known to cause chromosomal aberrations, micronuclei formation and DNA strand breaks in the majority of the cell d) MRAS

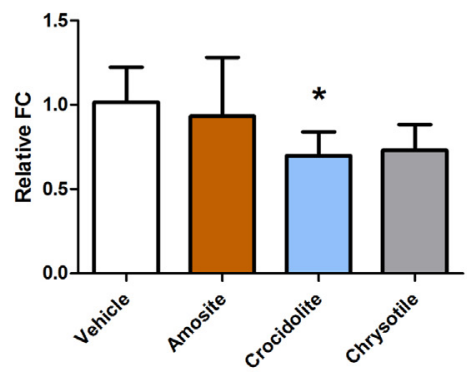

e) PIK3R5

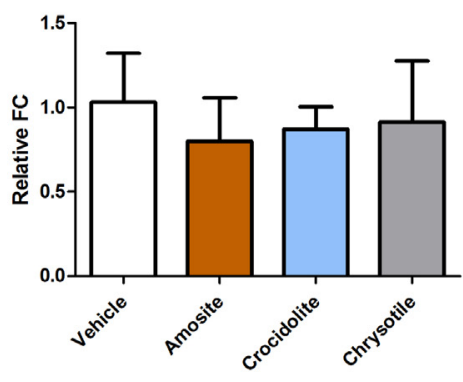

c) WNT7A

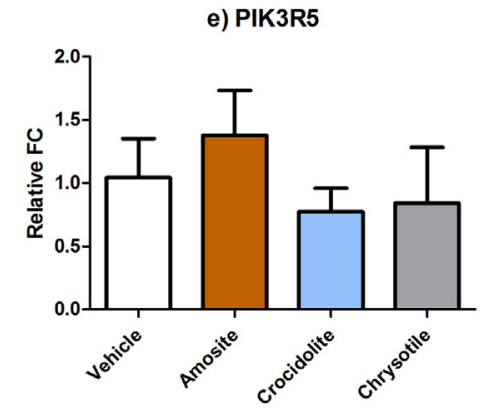

Fig. 5. Gene expression profiles of a) HOXB3, b) TCF7, c) WNT7A, d) MRAS and e) PIK3R5. The statistics were done using two-tailed t-test in control to vehicle controls. * indicates $p<0.05$. 


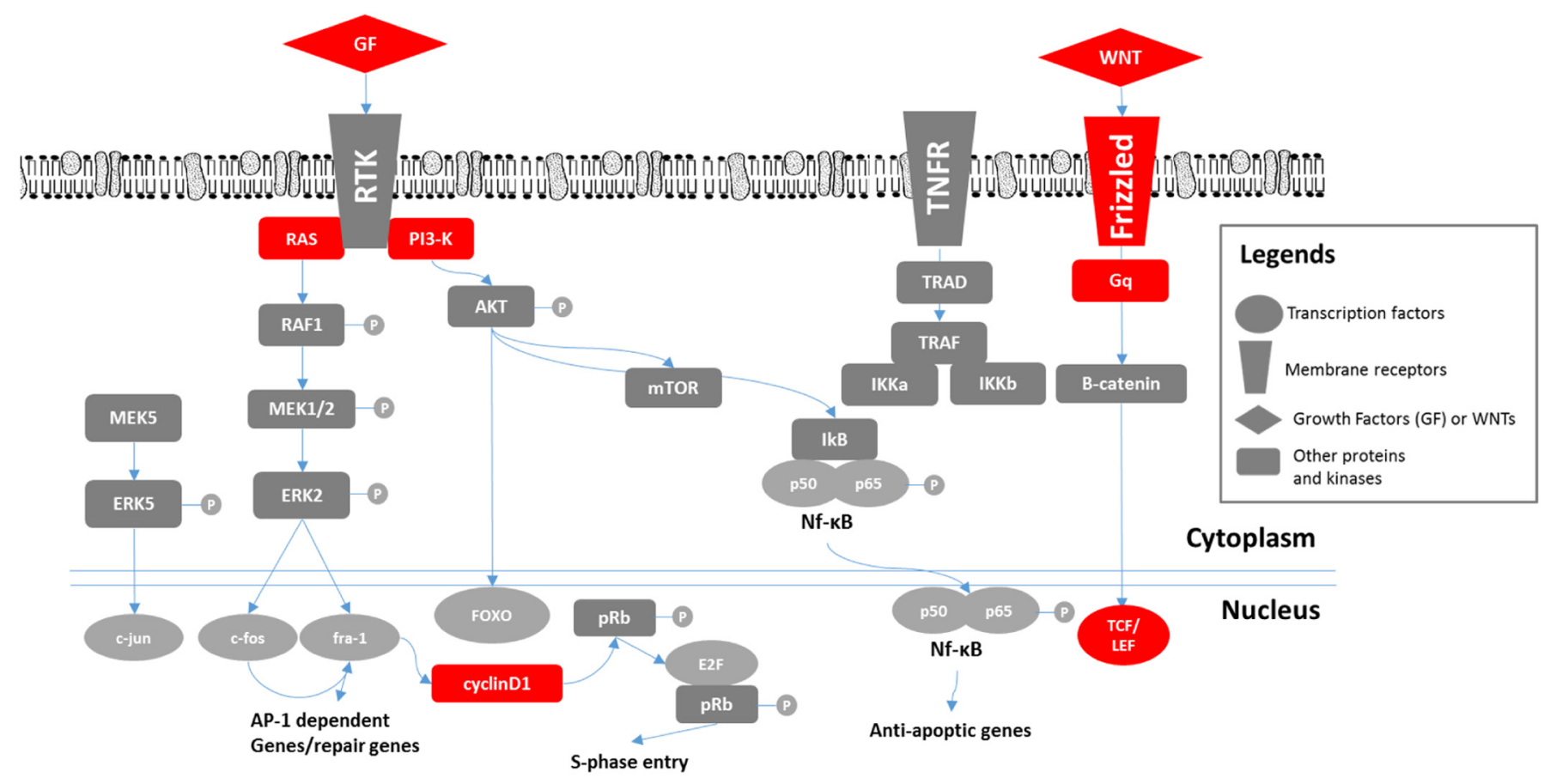

Fig. 6. Epigenetic contribution on signalling pathways altered after exposure to all types of asbestos, adapted from Mossman (2017b). The red coloured entities indicate differential methylation that is shared after exposure to amosite, crocidolite and chrysotile. (For interpretation of the references to colour in this figure legend, the reader is referred to the web version of this article.)

types at certain concentrations (Asakura et al., 2010; Dopp et al., 2005). In our study, at non-cytotoxic doses, an increase in DNA damage was detected by all types of asbestos. Interestingly, the exposure to chrysotile induced more DNA damage than amosite and crocidolite. This is interesting since amosite and crocidolite, in other word, amphiboles, are known to be more toxic than chrysotile. However, this could be due to the fact that chrysotile fibres might dissolve in the cellular lysosomes and increase DNA strand breaks in higher amount. The DNA-methylation alterations were assesses $24 \mathrm{~h}$ after exposure to a low amount of asbestos fibres $(2.5 \mu \mathrm{g} / \mathrm{ml})$.

Global methylation alterations were measured by LC-MS/MS, where the methylation of 5-mC was measured. In this study, we noted significant alterations of global DNA methylation changes (after amosite and crocidolite exposure, concentration $\geq 5 \mu \mathrm{g} / \mathrm{ml}$ ). Interestingly, no changes in global DNA methylation of chrysotile exposed cells was detected at the tested conditions. This difference between the different types of asbestos fibres could be because of the iron content in the structure of the amphibole fibres. Iron content of the amphiboles are known to increase the reactive oxygen species (ROS) content (Shukla et al., 2003). This oxidative stress might cause decrease in methylation in the DNA (Franco et al., 2008). In brief, oxidative stress can contribute to tumour development through alteration in genetics (i.e. increase in mutation rate, alterations on p53 signalling, ATM gene) and epigenetics. For epigenetics, it has been shown that increase in 8-OHdG on CpG dinucleotides inhibit the methylation by affecting DNA methyltransferase function (Turk et al., 1995). Another factor might be higher inflammation observed by amphiboles. NLRP3 inflammation and production/release of IL1 $\beta$, induced by asbestos fibres are linked with the development of malignant mesothelioma (Kadariya et al., 2016). It is shown that this inflammation induce demethylation and increased gene expression on the inflammatory genes during monocytemacrophage differentiation, suggesting a link between epigenetic changes and inflammation (Vento-Tormo et al., 2017). Nevertheless, since all the asbestos fibres are tumorigenic, we believe longer incubation time or higher concentrations of chrysotile, might generate loss of DNA methylation. It is noteworthy that amosite induced global hypermethylation whereas crocidolite induced global hypomethylation. We think this might be because of the dynamic nature of epigenetic changes in which the nucleus condensate and release because of the toxic exposure. However, more investigation might be necessary to study these changes. Nevertheless, this observation is not reflected in the CpG-specific analysis performed by Illumina450K showing only a small set of CpG's being hypermethylated.

$2.5 \mu \mathrm{g} / \mathrm{ml}$ of asbestos fibres were used to examine gene-specific DNA methylation alterations using illumina450K since this concentrations showed relatively lower genotoxicity. Hence, interference between genetic and epigenetic alterations is expected to be lower while analysing DNA methylation analyses. Nevertheless, vast changes in global methylation were also reflected on the CpG-specific whole genome methylation analysis by Illumina450K where a higher number of gene promoter and CPG site specific DNA methylation alterations were noted for amosite and crocidolite compared to chrysotile (approximately 10 times higher for amosites than for chrysotiles). Although exposure to chrysotile induced a less number of cytosine methylation alterations either by global DNA methylation or whole genome methylation analysis, a similar set of hypomethylated genes was noted compared to amosite and crocidolite exposure. Because it is known that all types of asbestos fibres contribute to lung malignancies, we focused on the genes that are differentially methylated by all types of asbestos exposure, in order to predict the mechanisms of epigenetic involvement in altered cellular signalling and cell differentiation.

\subsection{Overview of methylated genes and correspondence to the literature}

The most prominent altered signalling pathways in asbestos-induced pathogenesis include TNF signalling, NF-кB signalling, ERK signalling, PI3K-AKT signalling (Mossman, 2017b). The activation of these receptor-dependent or non-receptor dependent pathways contributes to the disease initiation from lung and mesothelial cells.

The DNA methylation changes, uncovered in this study, on these altered signalling pathways after asbestos exposure are depicted in Fig. 6. 
The effect of DNA methylation was seen on RAS oncogene, i.e. MRAS; PI3K group protein, i.e. PIK3R5 gene; Growth factors namely, i.e. fibroblast growth factor 20 (FGF20), fibroblast growth factor 6 (FGF6), platelet derived growth factor subunit B (PDGFB); on CyclinD1 (CCND1) gene; on frizzled receptor, i.e. frizzled class receptor 2 (FZD2); WNT factors, i.e. WNT10A, WNT11, WNT5B, WNT7A, GNAQ (Gq), TCF7 and LEF1 transcription factors. In addition, we observed increase in gene expression on PIK3R5 and TCF7 genes, in consistency with hypomethylation on the gene promoter.

These changes indicate epigenetic alterations on WNT signalling, hub-genes which controls downstream pathways and transcription factors which regulates cell cycle and transcription.

We know from the literature that different activations on receptor tyrosine kinases (RTKs) such as epithelial growth factor receptor (EGFR), fibroblast growth factor receptor (FGFR), MAPK signalling, ERK1/ERK2 signalling, PI3K-AKT signalling, cAMP play a role in asbestos-mediated malignancies in lung tissues (de Assis et al., 2014; Kanteti et al., 2016; Kawaguchi et al., 2009; Tamminen et al., 2012; Zhou et al., 2014). These pathways might be altered by alterations of the activity of kinases, transcription factors, (guanosine triphosphate) ases (GTP)ases, cAMPs and/or other regulators (Barlow et al., 2007; Mossman, 2017b).

Consistently, our analysis supported enriched DNA methylation alterations of 'MAPK signalling pathway', 'Rap1 signalling pathway', 'calcium signalling pathway', 'signalling pathways regulating pluripotency of stem cells', 'pathways in cancer', 'cholinergic synapse', 'oxytocin signalling pathway', 'glutamatergic synapse', 'cAMP signalling pathway', 'neuroactive ligand-receptor interaction', 'cGMP-PKG signalling pathway' after amosite and crocidolite exposure. In addition, using the GO analysis, we identified the majority of genes involved in transcription regulation. Gene functional classification analysis using shared/overlapped genes between all types of asbestos fibres, identified enrichment in following groups: Rho guanine nucleotide exchange factors and GTPases, homeobox genes, ATP-binding function, WNT group of genes.

The Rho family of nucleotide-exchange factors acts to switch the GDP-bound to active GTP-bound state. This set of genes recognizes extracellular signals and activates target downstream cellular signalling processes. For instance, the Rho guanine-exchange factors take a role in several cellular aspects including neuronal morphogenesis, muscle development and immune response(Schmidt and Hall, 2002). It is also suggested that Rho-GTPases are important factors for cell transformation and metastasis(Jaffe and Hall, 2002). We found that an exposure to amphiboles (amosite and crocidolite) induces hypermethylation on the $M Y O 9 B$ gene that is located on chromosome 19. The product of this gene acts as a GTPase activator for RHOA with SLIT2 interaction. Consistently, a study noted the hypomethylation on $M Y O 9 B$ gene as a potential tumour suppressor in lung cancer(Kong et al., 2015). In addition, the Ras-related protein 1 (Rap1) signalling was found to be enriched by amphibole exposure. Of note, Rap1 is a GTPase and controls diverse cellular signalling pathways including MAPK signalling, PI3K-AKT signalling.

The HOX group of genes is involved in developmental processes, and is also shown to be differentially methylated after exposure to asbestos. During embryogenesis, the proteins coded by the HOX group of genes act as important transcription factors that control embryogenesis (Montavon and Soshnikova, 2014). In cancer tissues, the upregulation or downregulation of several genes of the HOX group were noted dependant on the type of tumour (Bhatlekar et al., 2014).In a recent investigation, it has been found that the genes of the HOX group are dysregulated in malignant mesothelioma either acting as an oncogenic or a tumour suppressor (Morgan et al., 2016). HOXB4 expression was also associated with the overall survival of the patient (Morgan et al., 2016). Another study that was designed for the identification of epigenetic biomarkers of lung adenocarcinoma found that odd-skipped related transciption factor 1 (OSR1), single-minded family BHLH transcription factor 1 (SIM1) and HOXB3/HOXB4 regions might be associated with lung adenocarcinoma (Daugaard et al., 2016).

Tyrosine kinases, which act in the ATP-binding function, were also noted to be altered by exposure to asbestos. Tyrosine kinases transfer phosphate from ATP to proteins, switching these proteins on and off. DNA methylation alterations on a variety of tyrosine kinases will induce aberrant alterations in intrinsic cellular signalling such as MAPK and cAMP. Loss of gene expression of certain tyrosine kinases can be mediated by DNA hypermethylation at the early stages of cellular malignancy.

The WNT group of genes is another group of genes that has a role in the development, stem-nature of the cell and the disease (Klaus and Birchmeier, 2008). In our study, we found gene hypomethylation on WNT7A (tumour suppressor), WNT10A, WNT5B and WNT11 genes after all types of asbestos exposure. The role of WNT signalling in cancer, metastasis and immune response was also described (Zhan et al., 2017). WNT signalling takes an important role in lung development during embryogenesis (Pongracz and Stockley, 2006). Importantly, it is noted that methylation of the WNT7A gene is mediated by DNA methyltransfease 1 (DNMT1) and the gene was silenced in non-small lung cancer (Tennis et al., 2012). In addition, we identified alterations on other genes in WNT signalling, such as, FZD2 frizzled receptor, GNAQ. TCF7 and LEF1 transcription factors. Although no changes were seen on b-catenin, a hallmark of WNT signalling, downstream and upstream differential methylation can alter the expression.

Investigating the known cell-pathways that are altered by transcription after exposure to asbestos, we further investigated the involvement of DNA methylation changes. We found alterations on MRAS (RAS) gene which is located at the upstream of diverse cellular signalling pathways, i.e. PI3-K and AKT, MAPK signalling, ERK signalling and NF- $\mathrm{KB}$ signalling and downstream of receptor tyrosine kinases such as EGFR and FGFR. In addition, WNT signalling might contribute by epigenetic alterations to the cellular signalling and contribute to cellular aberrations (Inai, 2010).

Consequently, we found aberrant methylation on the hub-genes which regulate downstream signalling pathways after acute $(24 \mathrm{~h})$ of asbestos exposure. DNA methylation alterations on the gene promoter regions of the hub-genes are likely to alter the gene expression and alter the downstream pathways. Since microarrays may generate high number of false positives, we performed RT-PCR validations to conclude the observations. Exposure to the crocidolite significantly decreased the expression of MRAS gene, an important regulator of PI3-K, AKT, MAPK, ERK and NF- $\kappa B$, as dicussed previously. Downregulation trend of TCF7, HOXB3, PIK3R5 and WNT7A, also indicates a substantial alterations. However, a longer period of exposure or higher doses might be necessary to observe the alterations on these genes. Of note, hypomethylation of the gene promoter did not necessarily induced upregulation of the genes, indicating secondary mechanisms which may interfere with the transcription of the gene.

\section{Conclusion}

In conclusion, asbestos exposure altered global and gene-specific DNA methylation and the magnitude of alterations depends on the type of asbestos. Overall, the different types of asbestos induced alterations on similar sets of genes. A number of epigenetic alterations (gene promoter hypomethylation) in gene functional groups such as Rho mediated signal transduction, HOX genes, WNT genes, and genes that express RNA-binding proteins were noted after acute exposure to asbestos fibres. In addition, WNT signalling pathway was identified as an early contributor in asbestos-mediated cellular aberrations and methylation changes; its role might be critical in asbestos mediated pathogenesis. 


\section{Conflict of interest}

No conflict of interest was declared.

\section{Acknowledgements}

The authors thank Thomas Van Brussel for his technical assistance in microarray analysis. The study was funded by Stichting Tegen Kanker (agreement no: 2012-218, project no: 3M150270). Manosij Ghosh is the recipient of a European Respiratory Society RESPIRE postdoctoral fellowship (RESPIRE2 - 2014-7310).

\section{Appendix A. Supplementary data}

Supplementary data to this article can be found online at https:// doi.org/10.1016/j.envint.2018.03.031.

\section{References}

Aryee, M.J., Jaffe, A.E., Corrada-Bravo, H., Ladd-Acosta, C., Feinberg, A.P., Hansen, K.D., Irizarry, R.A., 2014. Minfi: a flexible and comprehensive Bioconductor package for the analysis of Infinium DNA methylation microarrays. Bioinformatics 30, 1363-1369.

Asakura, M., Sasaki, T., Sugiyama, T., Takaya, M., Koda, S., Nagano, K., Arito, H., Fukushima, S., 2010. Genotoxicity and cytotoxicity of multi-wall carbon nanotubes in cultured Chinese hamster lung cells in comparison with chrysotile A fibers. J. Occup. Health 52, 155-166.

Ashburner, M., Ball, C.A., Blake, J.A., Botstein, D., Butler, H., Cherry, J.M., Davis, A.P., Dolinski, K., Dwight, S.S., Eppig, J.T., Harris, M.A., Hill, D.P., Issel-Tarver, L., Kasarskis, A., Lewis, S., Matese, J.C., Richardson, J.E., Ringwald, M., Rubin, G.M., Sherlock, G., 2000. Gene ontology: tool for the unification of biology. Nat. Genet. 25, 25-29. http://dx.doi.org/10.1038/75556.

de Assis, L.V.M., Locatelli, J., Isoldi, M.C., 2014. The role of key genes and pathways involved in the tumorigenesis of malignant mesothelioma. Biochim. Biophys. Acta 1845, 232-247. http://dx.doi.org/10.1016/j.bbcan.2014.01.008.

Baccarelli, A., Bollati, V., 2009. Epigenetics and environmental chemicals. Curr. Opin. Pediatr. 21, 243-251.

Barlow, C.A., Barrett, T.F., Shukla, A., Mossman, B.T., Lounsbury, K.M., 2007. Asbestosmediated CREB phosphorylation is regulated by protein kinase A and extracellular signal-regulated kinases 1/2. Am. J. Phys. Lung Cell. Mol. Phys. 292, L1361-1369. http://dx.doi.org/10.1152/ajplung.00279.2006.

Baylin, S.B., 2005. DNA methylation and gene silencing in cancer. Nat. Clin. Pract. Oncol. 2, S4-S11. http://dx.doi.org/10.1038/ncponc0354.

Benjamini, Y., Hochberg, Y., 1995. Controlling the false discovery rate: a practical and powerful approach to multiple testing. J. R. Stat. Soc. Ser. B Methodol. 57, 289-300.

Bernstein, D., Dunnigan, J., Hesterberg, T., Brown, R., Velasco, J.A.L., Barrera, R., Hoskins, J., Gibbs, A., 2013. Health risk of chrysotile revisited. Crit. Rev. Toxicol. 43, 154-183. http://dx.doi.org/10.3109/10408444.2012.756454.

Bhatlekar, S., Fields, J.Z., Boman, B.M., 2014. HOX genes and their role in the development of human cancers. J. Mol. Med. Berl. Ger. 92, 811-823. http://dx.doi.org/10. 1007/s00109-014-1181-y.

Christensen, B.C., Godleski, J.J., Marsit, C.J., Houseman, E.A., Lopez-Fagundo, C.Y., Longacker, J.L., Bueno, R., Sugarbaker, D.J., Nelson, H.H., Kelsey, K.T., 2008. Asbestos exposure predicts cell cycle control gene promoter methylation in pleural mesothelioma. Carcinogenesis 29, 1555-1559. http://dx.doi.org/10.1093/carcin/ bgn059.

Christensen, B.C., Houseman, E.A., Godleski, J.J., Marsit, C.J., Longacker, J.L., Roelofs, C.R., Karagas, M.R., Wrensch, M.R., Yeh, R.-F., Nelson, H.H., Wiemels, J.L., Zheng, S., Wiencke, J.K., Bueno, R., Sugarbaker, D.J., Kelsey, K.T., 2009. Epigenetic profiles distinguish pleural mesothelioma from normal pleura and predict lung asbestos burden and clinical outcome. Cancer Res. 69, 227-234. http://dx.doi.org/10.1158/ 0008-5472.CAN-08-2586.

Churg, A., 1994. Deposition and clearance of chrysotile asbestos. Ann. Occup. Hyg. 38 (625-633), 424-425.

Consortium, T.G.O., 2015. Gene ontology consortium: going forward. Nucleic Acids Res. 43, D1049-D1056. http://dx.doi.org/10.1093/nar/gku1179.

Core Team, R., 2017. R: a language and environment for statistical computing [WWW document]. R Proj. Stat. Comput. URL. http://www.gbif.org/resource/81287, Accessed date: 14 March 2016.

Daugaard, I., Dominguez, D., Kjeldsen, T.E., Kristensen, L.S., Hager, H., Wojdacz, T.K. Hansen, L.L., 2016. Identification and validation of candidate epigenetic biomarkers in lung adenocarcinoma. Sci. Rep. 6 (35807). http://dx.doi.org/10.1038/srep35807.

Dopp, E., Yadav, S., Ansari, F.A., Bhattacharya, K., von Recklinghausen, U., Rauen, U., Rödelsperger, K., Shokouhi, B., Geh, S., Rahman, Q., 2005. ROS-mediated genotoxicity of asbestos-cement in mammalian lung cells in vitro. Part. Fibre Toxicol. 2, 9. http://dx.doi.org/10.1186/1743-8977-2-9.

Fischer, J.R., Ohnmacht, U., Rieger, N., Zemaitis, M., Stoffregen, C., Kostrzewa, M., Buchholz, E., Manegold, C., Lahm, H., 2006. Promoter methylation of RASSF1A, RARbeta and DAPK predict poor prognosis of patients with malignant mesothelioma Lung Cancer Amst. Neth. 54, 109-116. http://dx.doi.org/10.1016/j.lungcan.2006.
06.017.

Franco, R., Schoneveld, O., Georgakilas, A.G., Panayiotidis, M.I., 2008. Oxidative stress, DNA methylation and carcinogenesis. Cancer Lett. 266, 6-11. http://dx.doi.org/10. 1016/j.canlet.2008.02.026.

Godderis, L., Schouteden, C., Tabish, A., Poels, K., Hoet, P., Baccarelli, A.A., Van Landuyt, K., Godderis, L., Schouteden, C., Tabish, A., Poels, K., Hoet, P., Baccarelli, A.A., Van Landuyt, K., 2015. Global methylation and hydroxymethylation in DNA from blood and saliva in healthy volunteers, global methylation and hydroxymethylation in DNA from blood and saliva in healthy volunteers. BioMed Res. Int. BioMed Res. Int. 2015 (2015), e845041. http://dx.doi.org/10.1155/2015/845041.

Goto, Y., Shinjo, K., Kondo, Y., Shen, L., Toyota, M., Suzuki, H., Gao, W., An, B., Fujii, M., Murakami, H., Osada, H., Taniguchi, T., Usami, N., Kondo, M., Hasegawa, Y., Shimokata, K., Matsuo, K., Hida, T., Fujimoto, N., Kishimoto, T., Issa, J.-P.J., Sekido, Y., 2009. Epigenetic profiles distinguish malignant pleural mesothelioma from lung adenocarcinoma. Cancer Res. 69, 9073-9082. http://dx.doi.org/10.1158/00085472.CAN-09-1595.

Huang, D.W., Sherman, B.T., Lempicki, R.A., 2009. Systematic and integrative analysis of large gene lists using DAVID bioinformatics resources. Nat. Protoc. 4, 44-57. http:// dx.doi.org/10.1038/nprot.2008.211.

Humans, I.W.G. on the E. of C.R. to, 2012. Asbestos (Chrysotile, Amosite, Crocidolite, Tremolite, Actinolite and Anthophyllite). International Agency for Research on Cancer.

IARC Monographs, 2012. Arsenic, Metals, Fibres and Dusts (No. 100C). IARC.

Inai, 2010. Aberrant promoter methylation of WIF-1 and SFRP1, 2, 4 genes in mesothelioma. Oncol. Rep. 24. http://dx.doi.org/10.3892/or_00000875.

Jaffe, A.B., Hall, A., 2002. Rho GTPases in transformation and metastasis. Adv. Cancer Res. 84, 57-80. http://dx.doi.org/10.1016/S0065-230X(02)84003-9.

Kadariya, Y., Menges, C.W., Talarchek, J., Cai, K.Q., Klein-Szanto, A.J., Pietrofesa, R.A., Christofidou-Solomidou, M., Cheung, M., Mossman, B.T., Shukla, A., Testa, J.R., 2016. Inflammation-related IL1 $\beta / I L 1 R$ signaling promotes the development of asbestos-induced malignant mesothelioma. Cancer Prev. Res. (Phila.) 9, 406-414. http://dx.doi.org/10.1158/1940-6207.CAPR-15-0347.

Kamp, D.W., 2009. Asbestos-induced lung diseases: an update. Transl. Res. 153, 143-152. http://dx.doi.org/10.1016/j.trsl.2009.01.004.

Kanteti, R., Riehm, J.J., Dhanasingh, I., Lennon, F.E., Mirzapoiazova, T., Mambetsariev, B., Kindler, H.L., Salgia, R., 2016. PI3 kinase pathway and MET inhibition is efficacious in malignant pleural mesothelioma. Sci. Rep. 6 (32992). http://dx.doi.org/10. 1038/srep32992.

Kawaguchi, K., Murakami, H., Taniguchi, T., Fujii, M., Kawata, S., Fukui, T., Kondo, Y., Osada, H., Usami, N., Yokoi, K., Ueda, Y., Yatabe, Y., Ito, M., Horio, Y., Hida, T., Sekido, Y., 2009. Combined inhibition of MET and EGFR suppresses proliferation of malignant mesothelioma cells. Carcinogenesis 30, 1097-1105. http://dx.doi.org/10. 1093/carcin/bgp097.

Klaus, A., Birchmeier, W., 2008. Wnt signalling and its impact on development and cancer. Nat. Rev. Cancer 8, 387-398. http://dx.doi.org/10.1038/nrc2389.

Kodama, Y., Boreiko, C.J., Maness, S.C., Hesterberg, T.W., 1993. Cytotoxic and cytogenetic effects of asbestos on human bronchial epithelial cells in culture. Carcinogenesis 14, 691-697.

Kong, R., Yi, F., Wen, P., Liu, J., Chen, X., Ren, J., Li, X., Shang, Y., Nie, Y., Wu, K., Fan, D., Zhu, L., Feng, W., Wu, J.Y., 2015. Myo9b is a key player in SLIT/ROBO-mediated lung tumor suppression. J. Clin. Invest. 125, 4407-4420. http://dx.doi.org/10.1172/ JCI81673.

Krismann, M., Müller, K.-M., Jaworska, M., Johnen, G., 2002. Molecular cytogenetic differences between histological subtypes of malignant mesotheliomas: DNA cytometry and comparative genomic hybridization of 90 cases. J. Pathol. 197, 363-371. http://dx.doi.org/10.1002/path.1128.

Kulis, M., Esteller, M., 2010. DNA methylation and cancer. Adv. Genet. 70, 27-56. http:// dx.doi.org/10.1016/B978-0-12-380866-0.60002-2.

Laszlo, V., Hoda, M.A., Garay, T., Pirker, C., Ghanim, B., Klikovits, T., Dong, Y.W., Rozsas, A., Kenessey, I., Szirtes, I., Grusch, M., Jakopovic, M., Samarzija, M., Brcic, L., Kern, I., Rozman, A., Popper, H., Zöchbauer-Müller, S., Heller, G., Altenberger, C., Ziegler, B., Klepetko, W., Berger, W., Dome, B., Hegedus, B., 2015. Epigenetic down-regulation of integrin $\alpha 7$ increases migratory potential and confers poor prognosis in malignant pleural mesothelioma. J. Pathol. 237, 203-214. http://dx.doi.org/10.1002/ path. 4567.

Maksimovic, J., Gordon, L., Oshlack, A., 2012. SWAN: subset-quantile within array normalization for Illumina Infinium HumanMethylation450 BeadChips. Genome Biol. 13, R44. http://dx.doi.org/10.1186/gb-2012-13-6-r44.

Montavon, T., Soshnikova, N., 2014. Hox gene regulation and timing in embryogenesis Semin. Cell Dev. Biol. 34, 76-84. http://dx.doi.org/10.1016/j.semcdb.2014.06.005.

Morgan, R., Simpson, G., Gray, S., Gillett, C., Tabi, Z., Spicer, J., Harrington, K.J., Pandha, H.S., 2016. HOX transcription factors are potential targets and markers in malignant mesothelioma. BMC Cancer 16 (85). http://dx.doi.org/10.1186/s12885-016-2106-7.

Mossman, B.T., 2017a. Cell signaling and epigenetic mechanisms in mesothelioma. In: Testa, J.R. (Ed.), Asbestos and Mesothelioma, Current Cancer Research. Springer International Publishing, pp. 211-235. http://dx.doi.org/10.1007/978-3-319-535609.10.

Mossman, B.T., 2017b. Cell signaling and epigenetic mechanisms in mesothelioma. In Testa, J.R. (Ed.), Asbestos and Mesothelioma, Current Cancer Research. Springer International Publishing, pp. 211-235. http://dx.doi.org/10.1007/978-3-319-53560 9_10.

Mossman, B.T., Churg, A., 1998. Mechanisms in the pathogenesis of asbestosis and silicosis. Am. J. Respir. Crit. Care Med. 157, 1666-1680. http://dx.doi.org/10.1164/ ajrccm.157.5.9707141.

Nelson, H.H., Almquist, L.M., LaRocca, J.L., Plaza, S.L., Lambert-Messerlian, G.M., Sugarbaker, D.J., Bueno, R., Godleski, J.J., Marsit, C.J., Christensen, B.C., Kelsey, 
K.T., 2011. The relationship between tumor MSLN methylation and serum mesothelin (SMRP) in mesothelioma. Epigenetics 6, 1029-1034. http://dx.doi.org/10.4161/epi. 6.8.16074.

Ogata, H., Goto, S., Sato, K., Fujibuchi, W., Bono, H., Kanehisa, M., 1999. KEGG: Kyoto encyclopedia of genes and genomes. Nucleic Acids Res. 27, 29-34. http://dx.doi.org/ 10.1093/nar/27.1.29.

Pongracz, J.E., Stockley, R.A., 2006. Wnt signalling in lung development and diseases. Respir. Res. 7 (15). http://dx.doi.org/10.1186/1465-9921-7-15.

Raffn, E., Lynge, E., Juel, K., Korsgaard, B., 1989. Incidence of cancer and mortality among employees in the asbestos cement industry in Denmark. Occup. Environ. Med. 46, 90-96. http://dx.doi.org/10.1136/oem.46.2.90.

Robinson, B.M., 2012. Malignant pleural mesothelioma: an epidemiological perspective. Ann. Cardiothorac. Surg. 1, 491-496. http://dx.doi.org/10.3978/j.issn.2225-319X. 2012.11.04.

Schmidt, A., Hall, A., 2002. Guanine nucleotide exchange factors for Rho GTPases: turning on the switch. Genes Dev. 16, 1587-1609. http://dx.doi.org/10.1101/gad. 1003302.

Schmutte, C., Fishel, R., 1999. Genomic instability: first step to carcinogenesis. Anticancer Res. 19, 4665-4696.

Shukla, A., Gulumian, M., Hei, T.K., Kamp, D., Rahman, Q., Mossman, B.T., 2003. Multiple roles of oxidants in the pathogenesis of asbestos-induced diseases. Free Radic. Biol. Med. 34, 1117-1129. http://dx.doi.org/10.1016/S0891-5849(03) 00060-1.

Smyth, G.K., 2005. Limma: linear models for microarray data. In: Bioinformatics and Computational Biology Solutions Using R and Bioconductor. Springer, pp. 397-420.

Spandidos, A., Wang, X., Wang, H., Dragnev, S., Thurber, T., Seed, B., 2008. A comprehensive collection of experimentally validated primers for Polymerase Chain Reaction quantitation of murine transcript abundance. BMC Genomics 9, 633. http:// dx.doi.org/10.1186/1471-2164-9-633.

Spandidos, A., Wang, X., Wang, H., Seed, B., 2010. PrimerBank: a resource of human and mouse PCR primer pairs for gene expression detection and quantification. Nucleic Acids Res. 38, D792-D799. http://dx.doi.org/10.1093/nar/gkp1005.

Srivastava, R.K., Lohani, M., Pant, A.B., Rahman, Q., 2010. Cyto-genotoxicity of amphibole asbestos fibers in cultured human lung epithelial cell line: role of surface iron. Toxicol. Ind. Health. http://dx.doi.org/10.1177/0748233710374464.

Sugarbaker, D.J., Richards, W.G., Gordon, G.J., Dong, L., De Rienzo, A., Maulik, G., Glickman, J.N., Chirieac, L.R., Hartman, M.-L., Taillon, B.E., Du, L., Bouffard, P., Kingsmore, S.F., Miller, N.A., Farmer, A.D., Jensen, R.V., Gullans, S.R., Bueno, R., 2008. Transcriptome sequencing of malignant pleural mesothelioma tumors. Proc. Natl. Acad. Sci. U. S. A. 105, 3521-3526. http://dx.doi.org/10.1073/pnas. 0712399105.

Tamminen, J.A., Myllärniemi, M., Hyytiäinen, M., Keski-Oja, J., Koli, K., 2012. Asbestos exposure induces alveolar epithelial cell plasticity through MAPK/Erk signaling. J.
Cell. Biochem. 113, 2234-2247. http://dx.doi.org/10.1002/jcb.24094.

Tennis, M.A., VanScoyk, M.M., Wilson, L.A., Kelley, N., Winn, R.A., 2012. Methylation of Wnt7a is modulated by DNMT1 and cigarette smoke condensate in non-small cell lung cancer. PLoS One 7, e32921. http://dx.doi.org/10.1371/journal.pone.0032921. Tomasson, K., Gudmundsson, G., Briem, H., Rafnsson, V., 2016. Malignant mesothelioma incidence by nation-wide cancer registry: a population-based study. J. Occup. Med. Toxicol. 11 (37). http://dx.doi.org/10.1186/s12995-016-0127-4.

Tsou, J.A., Shen, L.Y.C., Siegmund, K.D., Long, T.I., Laird, P.W., Seneviratne, C.K., Koss, M.N., Pass, H.I., Hagen, J.A., Laird-Offringa, I.A., 2005. Distinct DNA methylation profiles in malignant mesothelioma, lung adenocarcinoma, and non-tumor lung. Lung Cancer Amst. Neth. 47, 193-204. http://dx.doi.org/10.1016/j.lungcan.2004.08.003.

Tsou, J.A., Galler, J.S., Wali, A., Ye, W., Siegmund, K.D., Groshen, S., Laird, P.W., Turla, S., Koss, M.N., Pass, H.I., Laird-Offringa, I.A., 2007. DNA methylation profile of 28 potential marker loci in malignant mesothelioma. Lung Cancer 58, 220-230. http:// dx.doi.org/10.1016/j.lungcan.2007.06.015.

Turk, P.W., Laayoun, A., Smith, S.S., Weitzman, S.A., 1995. DNA adduct 8-hydroxyl-2'-deoxyguanosine (8-hydroxyguanine) affects function of human DNA methyltransferase. Carcinogenesis 16, 1253-1255. http://dx.doi.org/10.1093/carcin/16.5. 1253.

Turner, S.D., 2014. qqman: An R Package for Visualizing GWAS results Using Q-Q and Manhattan Plots. bioRxiv 005165. http://dx.doi.org/10.1101/005165.

Vento-Tormo, R., Álvarez-Errico, D., Garcia-Gomez, A., Hernández-Rodríguez, J., Buján, S., Basagaña, M., Méndez, M., Yagüe, J., Juan, M., Aróstegui, J.I., Ballestar, E., 2017. DNA demethylation of inflammasome-associated genes is enhanced in patients with cryopyrin-associated periodic syndromes. J. Allergy Clin. Immunol. 139, 202-211.e6. http://dx.doi.org/10.1016/j.jaci.2016.05.016.

Wang, X., Seed, B., 2003. A PCR primer bank for quantitative gene expression analysis. Nucleic Acids Res. 31, e154.

Wang, D., Yan, L., Hu, Q., Sucheston, L.E., Higgins, M.J., Ambrosone, C.B., Johnson, C.S., Smiraglia, D.J., Liu, S., 2012. IMA: an R package for high-throughput analysis of Illumina's 450K Infinium methylation data. Bioinformatics 28, 729-730.

Ye, J., Coulouris, G., Zaretskaya, I., Cutcutache, I., Rozen, S., Madden, T.L., 2012. PrimerBLAST: a tool to design target-specific primers for polymerase chain reaction. BMC Bioinf. 13, 134. http://dx.doi.org/10.1186/1471-2105-13-134.

Zhan, T., Rindtorff, N., Boutros, M., 2017. Wnt signaling in cancer. Oncogene 36, 1461-1473. http://dx.doi.org/10.1038/onc.2016.304.

Zhou, S., Liu, L., Li, H., Eilers, G., Kuang, Y., Shi, S., Yan, Z., Li, X., Corson, J.M., Meng, F., Zhou, H., Sheng, Q., Fletcher, J.A., Ou, W.-B., 2014. Multipoint targeting of the PI3K/ mTOR pathway in mesothelioma. Br. J. Cancer 110, 2479-2488. http://dx.doi.org/ 10.1038/bjc.2014.220.

Zhuang, J., Widschwendter, M., Teschendorff, A.E., 2012. A comparison of feature selection and classification methods in DNA methylation studies using the Illumina Infinium platform. BMC Bioinf. 13, 59. 